\title{
A TRIAL TO ESTABLISH THE EFFICACY OF APPLICATIONS IN ATHLETIC INJURIES SPECIFICALLY USING HIRUDOID
}

\author{
R. L. McKECHNIE, V.R.D., M.B., Ch.B.
}

\section{M.D. Walsall Football Club}

Aims:-

In view of the large part played by rubefacients and similar rubbing ointments in athletic injuries to discover if one substance was better than another.

Method:-

The trial was carried out partly at Walsall and Aston Villa Football clubs. Physiotherapists at these clubs were given a form to fill in which stated:-

1. the name of the injured player

2. the diagnosis

3. the part of the body affected

4. the degree of severity

5. daily assessment of improvement

6. duration of treatment

The part of the body almost always affected in association football is the lower limb and this area proved to be of most interest and the trial was thus confined:-

i. muscle bruising - this was defined as an area of injury caused by a direct blow or strain not near ligaments.

ii. ligament injuries - an injury caused by overstretching of the ligament not in an area of large muscle bulk.

iii. haematomas - in this there was obvious discolouration. Haematoma was involved in both of the other injuries. In fact only one was treated specifically.

The total number of cases treated was 65 , of which Hirudoid was used on 36 and 29 were treated with previous standard ointments of a similar reputation. No double blind was tried because it was felt unfair to risk the players having any greater time out of their first team than was absolutely necessary.

The ointments were applied immediately after matches and sometimes at half-time, they were kept at the football ground and applied by the physiotherapist daily.

The injuries were defined as slight, moderate and severe.

a) slight - one which on first examination was not likely to keep the player off for more than a week.

b) moderate - one in which it was unlikely that the player would be fit for his next match. c) severe - one in which the period of unfitness was undefinable.

The distribution with regard to type with and without Hirudoid was as follows:-

\section{Table I}

$\begin{array}{lccc}\text { Hirudoid } & \text { Muscle Injury } & \text { Ligament Injury } & \text { Haematoma } \\ \text { With } & 19 & 16 & 1 \\ \text { Without } & 15 & 14 & 0\end{array}$

And with regard to severity-

$\begin{array}{llll} & \text { Slight } & \text { Moderate } & \text { Severe } \\ \text { With } & 5 & 23 & 8 \\ \text { Without } & 6 & 18 & 5\end{array}$

Actual days off were calculated from the day of injury until the player was able to take up his full time training again. This was judged by the player's ability to perform set tasks. The normal recovery programme is based on exercise to the limits of pain and the player with a lower limb injury is fit for full time training when he reaches the stage where whilst running at full speed, on a given signal, he can alter direction through $180^{\circ}$ without undue discomfort.

The results were as follows:-

\section{Table II}

$\begin{array}{llcc}\text { Hirudoid } & \begin{array}{l}\text { Muscle } \\ \text { Days off }\end{array} & \begin{array}{l}\text { Ligament } \\ \text { Days off }\end{array} & \begin{array}{l}\text { Haemat } \\ \text { Days of }\end{array} \\ \begin{array}{l}\text { With } \\ \text { Without }\end{array} & 2.9 & 3.7 & \\ & 3.3 & 7.1 & \\ & \text { Slight } & \text { Mable III } & \\ & & 4.3 & \text { Severe } \\ \text { With } & 1.8 & 5.5 & 6.2 . \\ \text { Without } & 1.9 & 5.6\end{array}$

Tables II and III are shown in histogram form in figures (1) and (2) respectively. 
Table showing comparisons between average days of treatment for slight, moderate, and severe injuries with and without Hirudiod.

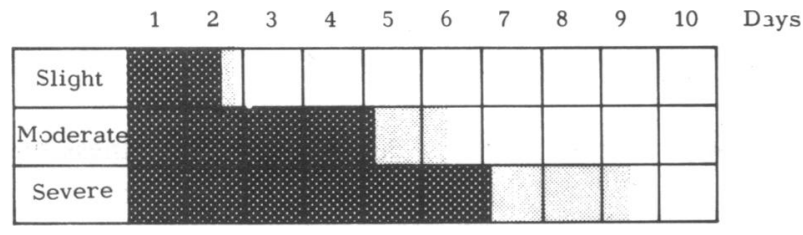

Fig. 1

Table showing the comparison between the average number of days treatment required with and without the use of Hirudiod on Muscle and Ligament injuries.
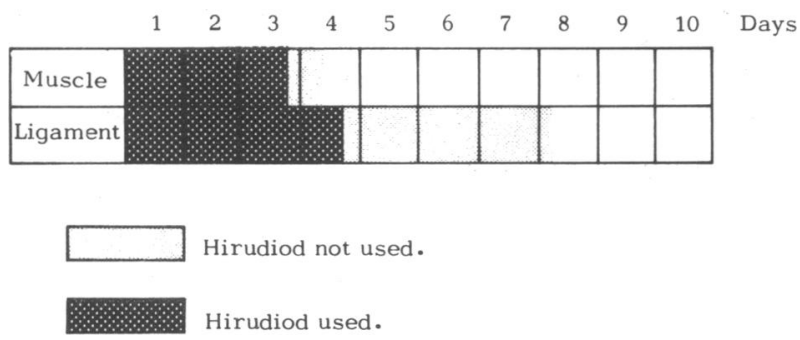

Fig. 2

\section{Summary:-}

The trial was simply carried out, but the Hirudoid was used first of all and it was obvious that the players preferred to use Hirudoid and so those with slight injuries tended to treat themselves and not report for treatment. There are therefore fewer cases of slight injury in the part of the series where Hirudoid was not used. It appeared, in fact, that the Hirudoid was more efficacious that other ointments, though only slightly. This seemed particularly so in the severe injuries, although the difference is greater, for severe cases, between the average time of treatment with Hirudoid than without, this is partly because of the amount of time involved i.e. that a severe injury takes longer to treat therefore the difference is greater.

The percentage benefit of using Hirudoid in severe cases was $10.6 \%$, in moderate cases $6.6 \%$ and in slight cases $2 \%$ so that there is a definite benefit of using Hirudoid over this number of cases.

Hirudoid is the best application for the treatment of minor injury used in this trial. This, however, was only a pilot trial and it would seem to suggest that a simple scheme like this carried out over a large number of people might find out one way or the other if applications of this nature are of any real benefit especially for severe and ligament injuries.

\title{
ANNOTATION
}

\section{LONGITUDINAL PULMONARY STUDY}

\author{
D. A. Brodie, B.Ed., M.Sc., St. Peter's College, Birmingham
}

A. M. Carlisle, S. R. I. Gough, S. Walker, Abingdon School, Berkshire

The cross sectional data presented earlier (Kamburoff and Brodie, 1970) have been repeated at yearly intervals over the last three years.

Forced vital capacity (FVC), forced expiratory volume in one second (FEV 1 ), the ratio of $\mathrm{FEV}_{1}$ over FVC expressed as a percentage (FEV\%) and forced mid-expiratory volume (FMF) were measured using a Vitalograph single-breath dry spirometer.

Height was measured to the last completed half centimetre using a wall-mounted stadiometer, and weight was measured on platform scales to the nearest half kilogram.

The results were analysed and their relationships investigated by application of standard methods of calculating means and standard deviations, coefficients of correlation, standard errors and probability levels. This was achieved by the facilities of the Atlas Computer Laboratory being made available to us.

The means demonstrate that peak velocity in all the measured parameters did not occur at the same time.

The coefficient of correlation of the same parameter between different years is highly significant for height, weight, FEV 1 and FVC. The coefficient of correlation of FMF between different years is significant $\left(\mathrm{pH}^{0} 01\right)$, and the same statistic for FEV\% is not significant. It should be possible to produce a regression equation for predictive purposes from this data.

It is hoped that a full report of this follow up study, already reported in Brit. Journ. Sports Medicine, Vol. V, pp. 140-145, 1970, will be published in the near future. 